\title{
Fostering Well-Being in Education Through Yoga and Mindfulness in the Snow (Snowga)
}

\author{
Leanne Glasser
}

\begin{abstract}
Through a program called Snowga (yoga in the snow), students learned about mindfulness and living in the present moment through yoga postures and meditations. Positive changes included growth in wellbeing as the children explored self, community, and the natural world through yoga, mindfulness, personal reflective journals, and artwork. The purpose: to engender awareness of the efficacy of mindfulness and yoga practices in nature and contribute to the growing body of knowledge around wellbeing in education.
\end{abstract}

\section{Background}

I have always been an advocate for getting students outside, experiencing nature, and playing. My own education had a heavy literature focus throughout my childhood and into my undergraduate years. However, I always felt drawn to the natural world. I loved being outside whether it was hiking or running on a trail, or enjoying a book under a tree in my backyard. After teaching abroad in South Korea for three years, I noticed that my students did not have the same opportunities to connect with the natural world that I had growing up. When I returned to my hometown for my master's degree program, I was fortunate enough to experience my first ever outdoor education course-on my first day of class no less. As the small class walked through the trails behind the school, the autumn leaves just changing colour, a quotation that I had not thought of in years danced through my mind. I loved literature and, in particular, loved Anne of Green Gables by L. M. Montgomery (1915):

It was November--the month of crimson sunsets, parting birds, deep, sad hymns of the sea, passionate wind-songs in the pines. Anne roamed through the pineland alleys in the park and, as she said, let that great sweeping wind blow the fog out of her soul. (p. 161)

It may not have been November at the time, but the bright colours, the cool breeze, and being in nature took me back to my childhood of imagining that I was Anne of Green Gables, curious, talkative, and in love with her surroundings. This connection to my childhood memories filled my heart with warm fuzzy feelings and I realized through this course that I was onto something very special. I learned to ask questions, to be curious, and to bring out the Anne Shirley that was within me. This deep love and connection with the beauty of all things around me made me realize that my passion, my calling, was to help students also find this sense of overall well-being. I decided to explore these ideas further in my thesis research as a way of helping students foster their own well-being in education. 
Through many of my readings-Mitchell Thomashow (1995) in particular-l realized that the connection and love that I felt could be defined as an "ecological connection" with the natural world. I discovered that so many before me felt these connections and this drive to do something with their understanding. For me, my passions are in education with elementary grades and with helping students to discover these inner connections to an outer world, as a way of promoting well-being. Thomashow (1995) wrote, "ecological literacy conveys an attitude, 'driven by the sense of wonder, the sheer delight in being alive in a mysterious, beautiful world" (p. 175). The concept of the world being "mysterious" and "beautiful" perfectly sums up my feelings and curiosity about the natural world. I wondered if there was some way that I could help others develop their curiosity about the natural world to foster their own well-being.

\section{Goals and Objectives}

My aim was to help students build an understanding of the natural world (through yoga movement, mindfulness, artwork, and meditation while enjoying, discovering, and being in the outdoors) as ways of discovering and nurturing well-being. I believe well-being and holistic education are interrelated. Holistic education is based on three basic principles: balance, inclusion, and connection (Miller, 2007). Through my research I found mindfulness, in a group setting, in the natural world, to be one means of achieving balance, inclusion, and connection (a sense of well-being). While mindfulness opens the possibility of finding connection (Rechtschaffen, 2014), the connection is incomplete if no link is made with the natural world; mindfulness can be a way of forming deeper connections while simultaneously situating the self as one with nature, rather than separate from nature (Fletcher, 2016). "Mindfulness means paying attention in a particular way: on purpose, in the present moment, and non-judgmentally" (Kabat-Zinn, 1994, p. 4). An example of a mindfulness exercise I used with my students was:

Find a comfortable seated posture. When you feel comfortable, close your eyes. Bring your attention into your breath. Notice how the breath feels. Notice that you are breathing in. Notice that you are breathing out. You don't need to change your breathing. Just notice it. Hear your breath. Feel your breath. Notice what it feels like. Now bring your attention to your heart. Feel your heart. Maybe you can feel it beating. Maybe you just know that it is beating. Try to give the feeling in your heart a name or a word that has meaning for you today. Notice what it feels like.

My well-being has changed for the better by being outside and taking time to identify with nature through mindfulness and movement. In reading the literature around student well-being, I came across Sauvé's (2009) framework. I wondered if I could observe well-being through a connection to the natural world by implementing adaptations to Sauvé's framework that included mindfulness and yoga practices in the outdoors. I hoped that I would observe positive changes in the students' well-being as they moved through the four levels of being. My conceptual framework centered well-being as the first level and central priority, followed by yoga and mindfulness practice as a way of executing self-care and wellness. The third level extended to connections from the self out into community and to place. The final level moved from community and place, to discussions about exploring and appreciating the natural world. Below I describe each of the four levels of the conceptual framework in detail, particularly how they interconnect with one another and how they helped me observe the positive changes in the students' overall well-being as part of the research project. 


\section{Conceptual Framework}

The conceptual framework used to structure or frame this research is an expanded version of a framework developed by Sauvé (2009). In her framework, she discusses three interrelated spheres of personal and social development: The Self; Other Humans; and the Environment (see Figure 1). Sauvé defines the meaning of environment within the spheres: "here the environment is certainly not just a context, scenery or set of manageable 'resources'. It consists of all levels of being and manifestation" (p. 330). Bringing the environment into all spheres is important, but a focus also needed to be placed on self. As a result, I placed "self" at the centre of my framework, within its core, and labelled it "emotional well-being of the students."

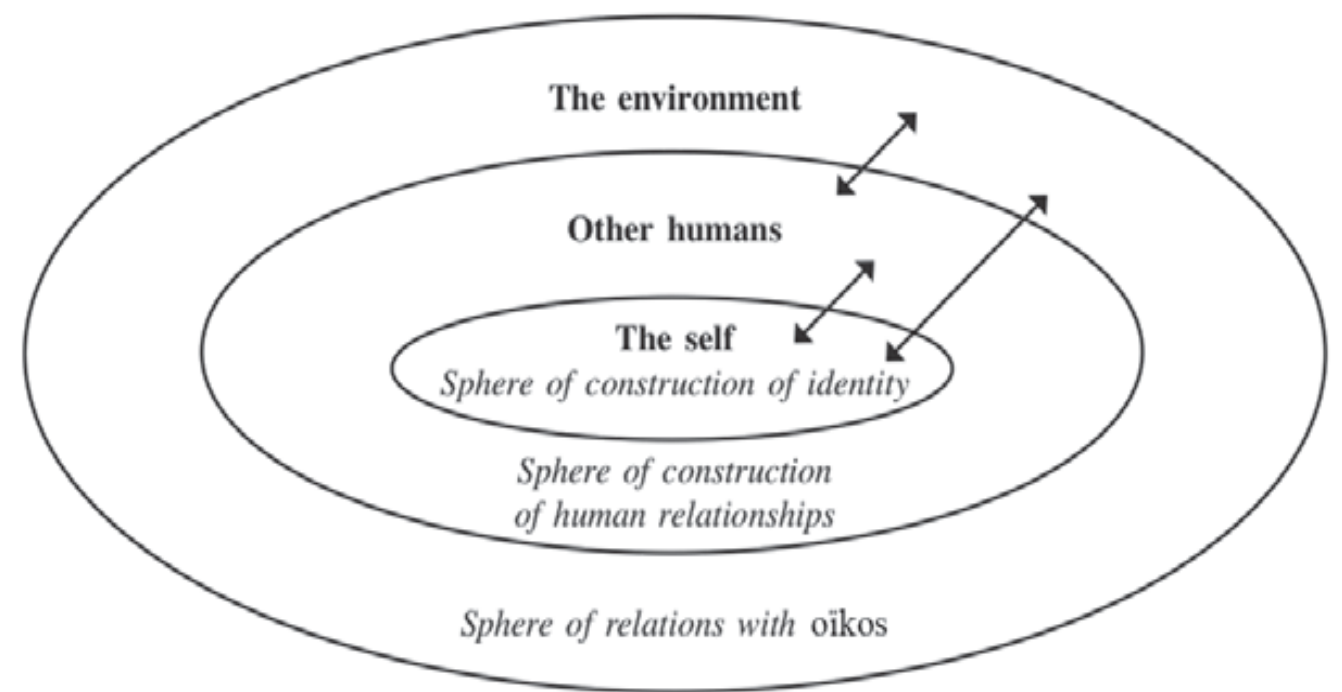

Fig. 1: Sauvé's (2009) three interrelated spheres of personal and social development (p. 330)

The second sphere focuses on the importance of human relationships with other humans. However, here too I suggested a revision to the model by including elements of mindfulness and yoga that can extend into the more-than-human community, rather than being limited to only other humans.

The third sphere focuses on relationship to the environment, but I suggested it is missing a step that allowed students to feel connected to community and a specific place. The important constituent here is the connection between the learner and the place that allows for student learning to occur. Finally, an additional sphere to deepen Sauvé's (2009) framework is inclusion of connection to the natural world through mindfulness, yoga movement, and connection to place to foster overall well-being. This sphere acts as the connection to the natural world that links all other spheres together (see Figure 2). In re-visioning and subsuming Sauvé's tenets, this conceptual framework included student well-being at its core and environmental connections at its periphery; the revised model worked more cohesively for this research. 


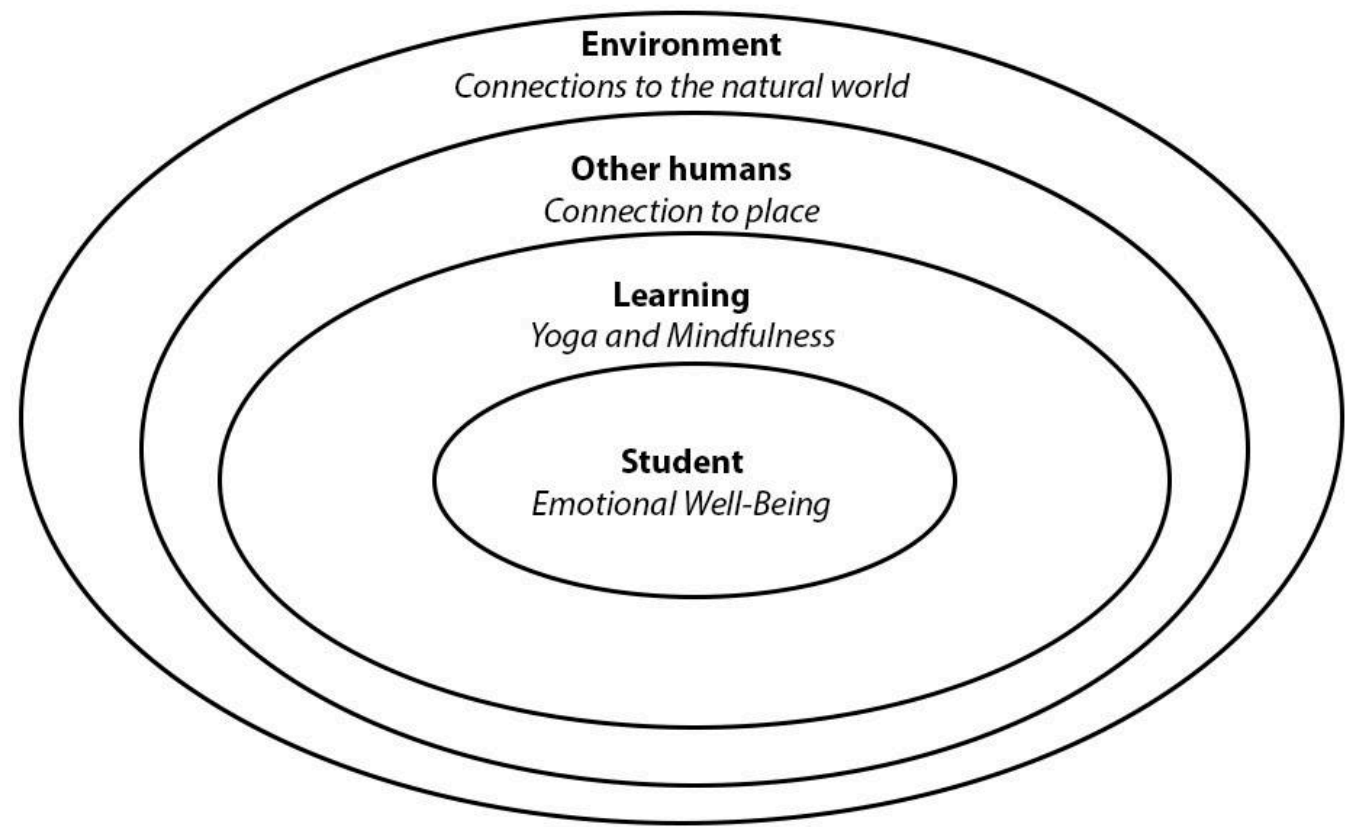

Fig. 2: Author's conceptual framework for this research, adapted from Sauvé's (2009) framework

My research attempted to fill a gap in the research literature. While some research has been conducted on mindfulness and its benefits (e.g., Noddings, 1992; Rechtschaffen, 2014; Bai \& Cohen, 2008), there has been little research that examines yoga and mindfulness as a form of environmental education that nurtures student well-being. Using my conceptual framework, I investigated the various spheres while exploring the natural world through yoga and mindfulness and their connections to student well-being.

\section{Research Question/Methods}

How does moving through the four interrelated spheres of the conceptual framework allow students to express their feelings and expressions of well-being? Through artwork and discussions, the students showed me the connections they made to nature, to their community, and to their well-being by exploring yoga and mindfulness in the natural world. I interpreted their journey of discovering deeper connections to their own well-being through narrative reflection as researcher-educator.

Specifics of the study. This research study was conducted during a community-based children's yoga program that I led with four elementary-aged student participants. I had three primary sources of data: circle discussions, student journals (which included artefacts like drawings and poetry), and my own researcher journal. For the circle discussion groups, I made brief notes during the discussion of main points or phrases that felt meaningful to me and to my research. Immediately following the classes, I would then go home and spend two to three hours journaling and reflecting on what was said by the students, interpreting using my conceptual framework. During this time, I practised self-reflection, one of the four levels of reflections in education — surface, pedagogical, critical, and self-reflection- described by Larrivee and Cooper (2006). After each class, I would make notes about the students' journals and what they shared with the group. One aim was to develop and document my understanding and 
interpretation of student connections to well-being through my conceptual framework. As an educator, I wanted to teach about feelings that led to my interpretation of well-being through discussions of understanding, compassion, love, wholeness, and inclusion. The discussions and journal entries were inspired through yoga and mindfulness in the natural world. I wanted to authentically record in my reflection journal what I saw and felt when observing and conversing with the students.

The classes were held once a week for one hour with each session focusing on a new mindfulness component, yoga practice, and outdoor experience. The lessons on mindfulness and meditation were inspired by Rechtschaffen's (2014) eight-week lesson plans of: "Opening mindful moment; check-in and report back; new lesson introduction; practice; sharing/council; journaling/artwork; world discovery; closing mindful moment" (p. 145). Each class comprised a journaling component both prior to and following an outdoor yoga and/or mindfulness experience and the creation of an artistic piece by the group. Each component of the class took between 15 to 20 minutes of the hour. I believe that this flow matched well with my framework of four spheres: student emotional well-being; learning yoga and mindfulness practices; connection to place and community; and connection to the natural world (see Figure 2). Each of these spheres was included in each of the eight lessons designed to deepen students' mindfulness and ecological literacy through yoga practices and, in turn, their well-being.

\section{Gathering Data}

The required ethics approval was obtained from my home university's Research Ethics Board. I took notes during each class based on observations of the students' body language, word choice, and facial expressions. These notes were taken while the students were speaking. I had discussed at the beginning of the first session that I would be writing notes and there were no "wrong answers." I would jot down a phrase or key points to help me remember what was talked about, then, after the session was complete, wrote reflections in my researcher journal. I did this in a quiet location that allowed me to write undistracted. Using my notes to help me remember smaller details, I relied heavily on my memory and the feelings that I had while observing the students' journals, discussions, and actions.

The group circle discussions pertained to topics that emerged naturally during student conversations. I prepared questions ahead of time to kick off discussions, but many times the topics veered off from where I thought we might go, which was fine given I wanted to see what naturally emerged. Each session would typically begin with a conversation about their journals that they would show me when they entered the room. These gave me a window into what was on their minds and a starting place for discussion. Later, as we ventured outside we would talk about natural things that we saw. I would ask about the weather or wonder out loud about something that we encountered on the walk outside. The students had the opportunity to express their thoughts, opinions, and ideas in each class through their journaling, movement (yoga postures), pictures, poetry, dance, speech, or any other form of communication they chose. I welcomed all forms of art and communication. To aid my memory, I took photos of their drawings and journals after the session was complete. I would always ask their permission before I took a photo and every time I asked, all four students gave me permission. I always made sure 
their names and faces were not obvious in any of the photos and would upload them onto my computer at home and save them under their pseudonyms.

\section{Analyzing the Data}

Once the data were gathered, I analyzed them by using my conceptual framework (see Figure 2). I reflected on the sessions: what was talked about, what the students drew or wrote in their journals, and what happened while we were outside doing yoga and engaging in mindfulness practices. I linked my observations to the four spheres of my conceptual framework. For example, if a student talked about how mindfulness helped them feel peaceful, I would link that to the mindfulness sphere and note that feelings of peace applied also to the student's overall well-being.

It was through rich description that the presentation of the findings became trustworthy. Following Patton (2002), trustworthiness was built through three ways of data gathering: open-ended conversations, direct observation, and written documents. In my study, the written documents were the notes and my research journal as well as student artwork, poetry, and journals. I took the students' words and artwork as representations of their connections with the natural world as interpreted through me. I attempted, as best as conceivably possible, to maintain neutrality and to listen and see (facial/body cues and expressions) what the students were saying. I could not actually know what students were thinking and feeling, but I felt that through our conversations and my observations I could interpret their words authentically and then link them to the conceptual framework.

\section{Findings and Discussion}

To protect the anonymity of the students, their names have been changed to pseudonyms that I assigned. Dakota was 11; Devon is Dakota's brother, 9 and the only male student in the class; Casey was 11; and Jamie was 9, and had just moved to Canada from the United States. Jamie joined Snowga one week later than the rest of the group.

Themes. The following section outlines the themes from my conceptual framework: moving through the spheres beginning with student emotional well-being, to learning yoga and mindfulness, then to connections to community and place, and finally connections to the natural world.

Sphere one: Student emotional well-being. This sphere was one of the easiest spheres for the group to move through. The students' journals showed me where the students were each day at the beginning and end of the sessions as they could articulate what was on their minds in those moments. They often began the sessions by focusing on either past or future events. Typically, the first journal of each class portrayed an intense emotion, either something they were very excited about or something that they were very upset about, with some even describing both in the same entry. One example can be found in Devon's journal entry (see Figure 3) where he lost his mitten on the way to Snowga. An excerpt from my reflective journal read: 
He entered our room visibly distraught: his eyes and face were red and he was sniffing back tears as he told us, "I lost my mitten and it was really important to me. My mom and dad said they would look for it, but I think it's gone." He buried his face in his elbow on the table. His sister Dakota patted him gently on the back, "We'll find it," she whispered. Everyone including me nodded in agreement. "We'll all keep our eyes peeled for it when we walk outside to our spot under the tree. Maybe it fell near the entrance," I suggested. When we finished the Snowga lesson, the mitten was still nowhere to be found, but Devon appeared to be much more cheerful and did not mention the mitten again. Luckily, at the end of class when his parents picked him up, they brought good news. They found the mitten in the driveway at home!

I found the transition between the first and second journal entries of each child interesting; it varied among students over the weeks depending on what was going on in each student's life. As a class, we spoke about being in the present moment as mindfulness.

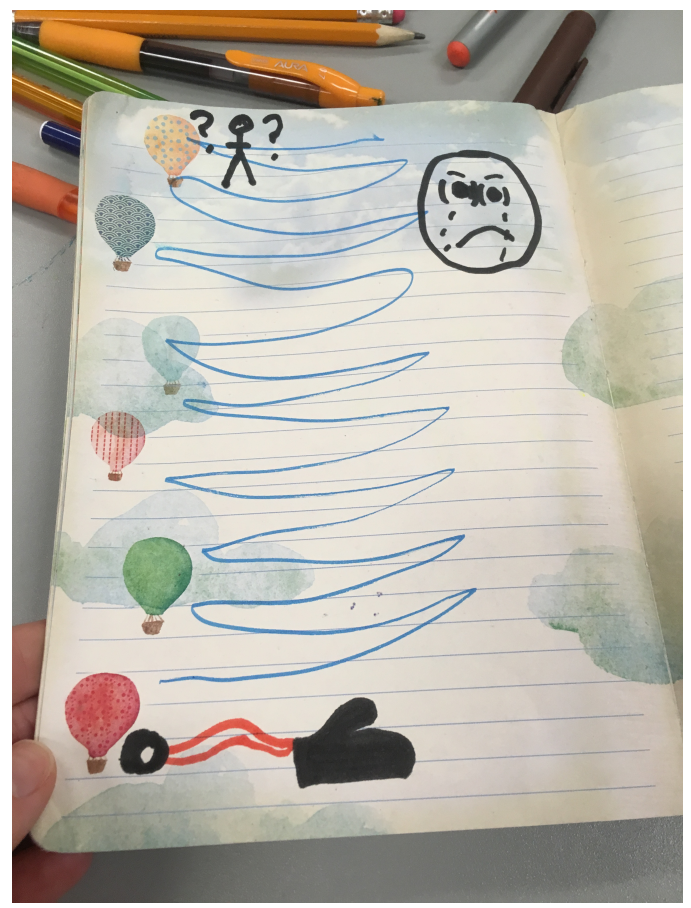

Fig. 3: Devon's "Missing Mitten" journal entry

Sphere two: Learning yoga and mindfulness. Yoga and mindfulness (in the natural world) were the key elements of Snowga and the backbone of the entire conceptual framework. Each week through yoga and mindfulness, I watched the students form stronger connections to each other and to the place where we practiced. The students showed through their journaling-typically in their second journal entry of the session-that they were shifting from a past or future focus to mindfulness. I believe that this shift came, in large part, because the yoga and mindfulness exercises were conducted outside.

I observed and later wrote about the transformation I witnessed in the students each time we went outside. In doing yoga exercises-whether partner yoga (yoga poses done with a partner, in unison, focusing on breathing together and moving together), chanting ohm together, stretching, sequencing, or group work -the students experienced the outdoors together as a group and, in turn, grew as a group. An example 
of their growth as a group came from observing the smiles and the laughter (signs I interpreted as visual well-being) as they became more comfortable with one another over the weeks. I also noted they were more playful in their movements outside than when sitting inside around a table, on hard plastic chairs. The squirming and moving was welcome outside, while in the classroom they appeared less comfortable.

Following our nature walk, the students depicted their experiences in their journals, which they then shared in circle discussions. Casey described a drawing that focused on her five senses: "Touch-I couldn't feel anything because of my mittens, but I could feel that I had warm hands. The sound was quiet-I drew squiggly lines. Taste-it was nothing. Smell-I smelled fresh air outside, but now I smell chlorine inside. See-I could see the sunset-it represents nature and my heart" (see Figure 4). Moving through all five senses is a good example of what mindfulness is about, experiencing the world in different ways, in the present moment, as it exists and as you exist. Casey, using the description of "warm hands" and drawing the calm squiggly lines to show quiet and peace in light blue hues, showed me where she was in that moment; Casey was present, in the field, feeling and reflecting on being in nature. Again, it was more than her words I was interpreting, but also the colours, her calm smile, and the deep inhale as Casey said, "I smelled fresh air outside." I must admit that the contrast between the fresh air and the smell of chlorine in the Sports Complex was surprising to me. Although I had noticed the smell of chlorine myself, I did not think that the smell would enter into their journals. Casey showed me that through all her senses, she was comparing the peaceful sensations of being outside (in the cold, no less) with the warm, chemical-filled air inside.

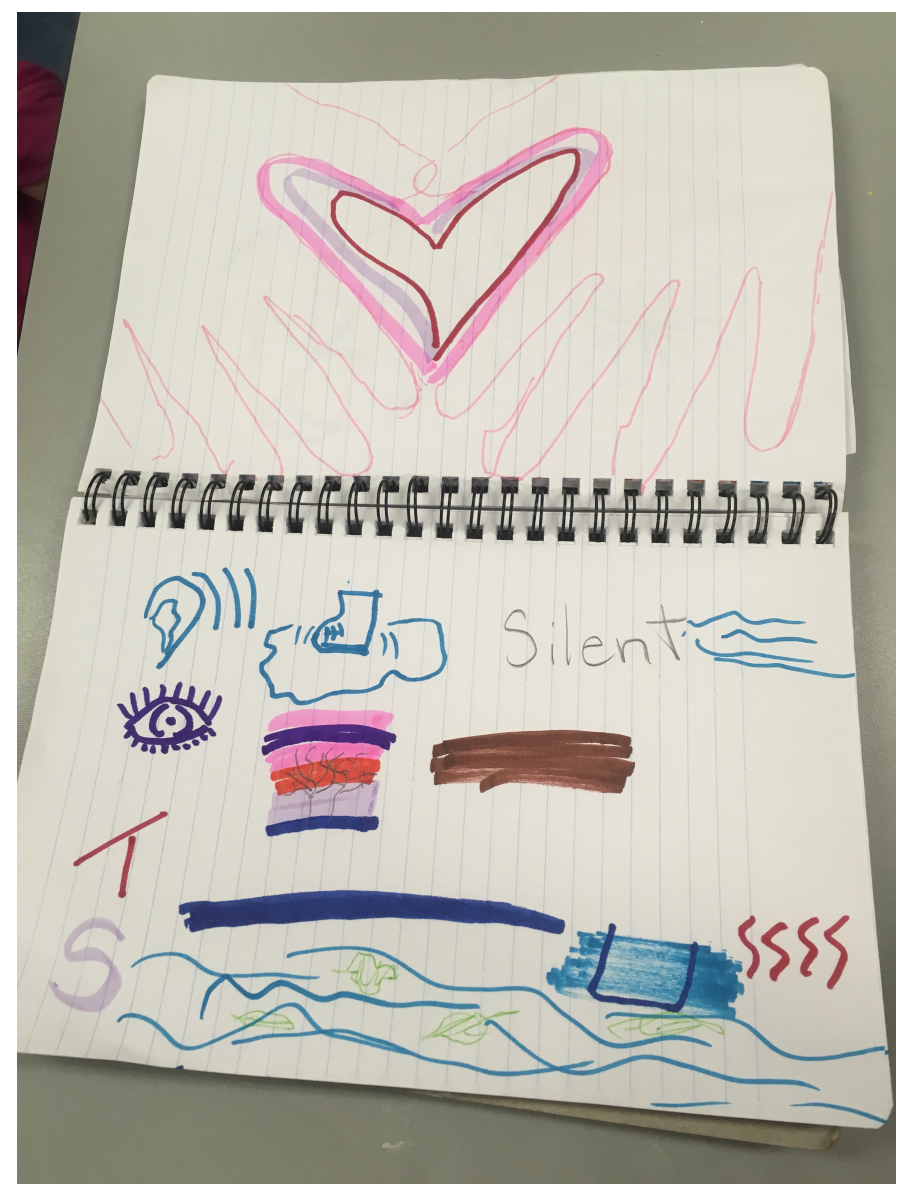

Fig. 4: Casey's "Five Senses" journal entry 
Sphere three: Connections to community and place. These two concepts did not correlate the way I expected them to. I speculated that the students would bond as a group and, together as a close community, immediately feel a strong connection to the place where we practiced, and that this would be represented in their journals. While they did make some connections to place-the field where we practiced each week — by the time we traveled back inside to journal, I think they forgot about these connections and focused on what might have been the more fun parts of their outdoor experience. While we were outside they were playful and clearly enjoying being outside in a natural area, as I mentioned before, only sometimes they would write about their nature connection in their journal and other times they would write about their plans for later that night.

I did notice that each week the relationships among the students appeared to deepen, including into new friendships for those who did not previously know each other. I suspect this was largely due to partner and group yoga as I purposely paired them with a different partner each week. Dakota and Devon were siblings and both were friends with Casey before starting Snowga. Jamie was new to the group and at first participated by playing and exploring on her own, but by the end of the course in its entirety she would strike up conversations with Dakota, Devon, and Casey, seemingly comfortable. They talked about things they had in common or shared feelings about their outdoor experiences. The students told me throughout the sessions that they felt a connection to each other as a group, especially when they would hold hands in partner or group yoga. I too felt that connection and interpreted it as a positive outcome promoting the students' overall well-being.

Sphere four: Connections to the natural world. While the students were outside exploring, and enjoying the sunsets, genuine conversations occurred where they questioned and played freely. The words they used to describe their experiences were positive and enlightening.

Here is an excerpt from Week 7 of my journal that describes a typical moment we experienced together outside and the connections made by the children:

We decided to take a wander through a small thicket of trees after yoga. The snow was very crunchy on top, but soft and deep underneath. The children enjoyed the experience of their feet falling through the snow; they had to struggle just to walk and laughed out loud as they helped one another out of the snow. As soon as we arrived by the trees-a mix of pine, birch, and cedar - Casey shouted, "Watch out for the rabbit poop!" Jamie was really interested in seeing the animal tracks and asked how long ago the tracks were made. Devon speculated that they looked pretty fresh. We walked by a big cedar tree and everyone climbed or touched the tree in some way. They seemed to enjoy the rough feel of the bark and the winding, meandering creases in the wood. Like the animal prints in the snow, the tree had untamed trails and grooves in its trunk as its bark naturally twisted up the tree. Jamie lifted a snow-laden mitten to move her hat that had gone awry and pointed to the top of the tree, "Hey, I think I see a nest or something up there." I asked where that nest might have come from. Everyone gathered at the root of the tree and stared skyward. Puzzled, Jamie was frozen in place, but Casey started reaching for lower branches trying to hoist herself higher up. Devon spoke through squinted eyes, "I see white! Like egg shells! It must be a bird's nest!" The energy level soared. Everyone nodded in agreement, craning their necks to get a better look. "Yep. That's what it is," he confirmed. 
Before heading back inside, Dakota made a smiling face in the snow, cut it out, and because it was firm and sticky, was able to place it on the tree so others could see it (see Figure 5). Casey laughed and said the smiling face looked a bit like a scary face. Dakota told me, "I really like that the snow was so hard that I could cut out a mask from it. I hope people know that this is a happy face." Casey assured her that people would know. As we walked back inside, Dakota wondered if the mask would still be there by next week.

I could see glimpses of how our time together showed the students what it means to care for the self through mindfulness, and helped them develop a little community. By connecting with the self through movement, the students articulated in their journals and group discussions how they were able to release their stress through play, curiosity, yoga, and mindfulness. I argue that this is something that should be available for all students, not just those few, like these students, who register for a community recreation program like Snowga. I have learned much from this research and I feel comfortable looking forward and making some recommendations for both practice and future research.

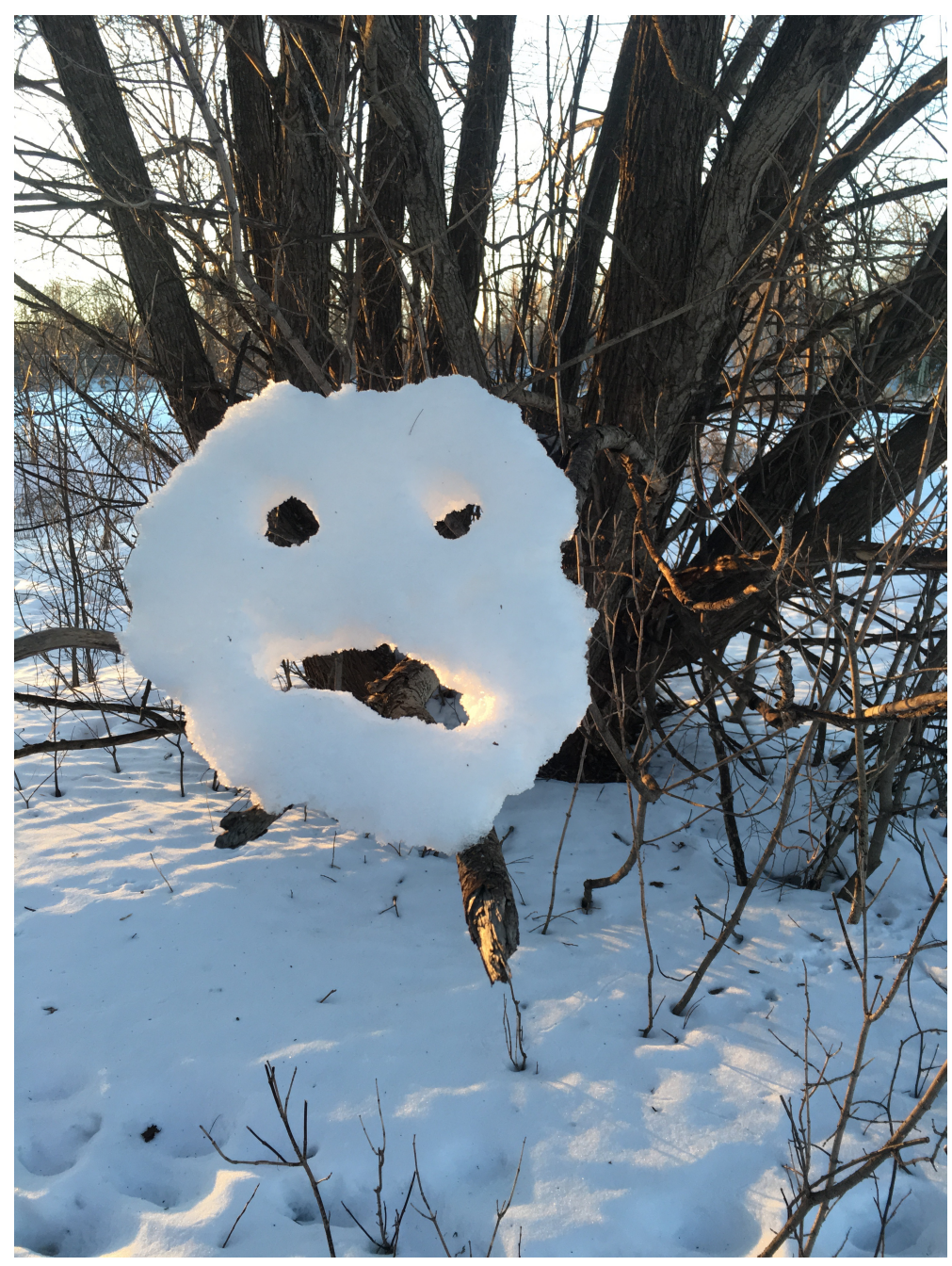

Fig. 5: Dakota's smile mask 


\section{Implications for Practice}

First, I would recommend to teachers that yoga and mindfulness be incorporated in the classroom. In many cases teachers do not have the background or the training in mindfulness and/or yoga, so the first place to begin would be to implement teacher training into schools or provide incentives to motivate teachers to practice mindfulness and yoga in the outdoors on their own time. My opinion is that once teachers realize the benefits that come with practicing yoga and mindfulness regularly, they will feel inspired to implement it into their everyday schedules in their classroom. Yoga and mindfulness practices do not need to be relegated to an afterschool program, but neither do they need to be limited to specially allocated times during the day. Rather, these practices can be used frequently, whenever students need time to refocus (Hitzhusen, 2006). I realize that not every teacher will find the passion and motivation to implement or practice yoga and mindfulness on their own time, but my hope is that through research like mine teachers will find inspiration to bring these ideas into their classrooms and into their own lives.

I believe that this method of teaching can play an important part in promoting student well-being as a way of teaching about the self, mindfulness, yoga, community and the natural world. I think that my research is valuable because it provides some evidence that the techniques that I used, as derived from my sources (Adele, 2009; Kabat-Zinn, 1994; Meiklejohn et al., 2012; Rechtschaffen, 2014; Sauvé, 2009; Shanker, 2013; Stone, 2008; Zabel, 2013), may be effective in helping guide students to learn about, feel comfortable in, and feel connected with their well-being. Yoga and mindfulness practiced outside offers

an opportunity to quiet the mind and body and appreciate what surrounds us here, in this present moment.

This research and method of teaching echoes the growing awareness that we, as educators, need to craft ways of enhancing the mental health and well-being of children. We need to develop new, or recover old, ways and focus our classrooms on the well-being of students. These practices are thousands of years old and based on traditions that have been proven in the past to bring peace and well-being to its practitioners (Rechtschaffen, 2014). It is important to schedule time for students to pause, reflect, meditate, and enjoy the present moment, and to just be children.

\section{Implications for Research}

In terms of future research, there is so much more that remains to be discovered about the potential role of yoga and mindfulness in the natural world in order to foster student well-being. Conducting research on programs like Snowga with more students and over a longer period of time-over the course of a few months or a year, for example-would provide us with a better idea of how deep the learning and connections might go. I feel like we just skimmed the surface of what these students were feeling and were capable of. Through observations of and conversations with the students, I noticed that each moved through the four spheres identified in my framework. I imagine that with longer sessions several times in a week, there is real potential here for integrating yoga and mindfulness as a way of fostering well-being through connection to place and the natural world. I would like to see more research on this topic to see if my hunch is correct. 
Limitations. There are always limitations in research, I can identify a number of limitations in mine. First, my research involved only four children between the ages of nine and eleven years who were fairly homogenous in their backgrounds. The generalizability to larger groups and students of different ages of learners is thus limited. One flipside of this limitation, however, with a small class of four, I was able as an educator to give each of the students much attention and as a researcher there was time for each of them to speak and be heard by all members of the group. Another limitation is that having only one hour for each session made it difficult to complete everything I originally planned and to have space for emergent conversations to fully unfold. Having more time would have benefitted the group, so if this program was to be implemented in a school setting, I would recommend more time be allotted.

\section{Final Reflection}

Close your eyes for a moment and take in a long, deep breath. No matter where you are in the world, imagine that breath is full of fresh, clean air. Imagine the taste of that air as it fills your lungs. Feel your belly expand with air, as if your lungs just cannot get enough of it. When your breath is as full as can be, pause for a moment before slowly exhaling all the air back out. Imagine that each time you breathe in, you breathe in that fresh, cool, air with a familiar lingering scent. Feel all your stresses melt away as you release not only the breath, but any tension you're holding as well. Enjoy that moment of "freshness" as my students would say. An excerpt from my last reflection speaks to my final thoughts as researcher/educator:

As I walk out of the building, into the parking lot towards my car, my head swirls for just a second. I stop to catch myself and the realization hits me-Snowga is over. In a moment of reflection, I find myself feeling sad, nostalgic even. I gaze across the fenced lot to the field where we spent eight evenings. I wonder when I'll look over at that field or sit there again. Will my students stop by and explore the thicket of trees without me? Will they be inspired to explore other thickets? Did I fulfill my "teacher" duties for these students? Did I accomplish all that I set out to do?

In those last moments before heading home, my heart was full of hope. Although it had only been eight short sessions, I felt I was leaving a class I had taught for a year. I knew these students and felt a connection to them and to our special place. I realized right then and there that this love of teaching was the reason that I first entered the field of education. I feel passionate about inspiring those around me to feel balanced, included, and connected (Miller, 2007). Everyone deserves to feel love, affection, and belonging, and everyone deserves to interact with the natural world. The Anne of Green Gables within me would be proud.

Movement, breath work, mindfulness, community, and place are all elements that bring benefits to our lives and that engender light and warm fuzzy feelings in the heart. They promote an "ecological connection" (Thomashow, 1995) with the natural world and an overarching sense of well-being. Everyone deserves this, and I believe it is my job to bring the mystery, beauty, curiosity, and positive feelings that are important in ecological connection to benefit students' overall well-being. 


\section{References}

Adele, D. (2009). The yamas and niyamas: Exploring yoga's ethical practice. Duluth, MN: On-word Bound Books.

Bai, H., \& Cohen, A. (2008). Breathing qi, following dao: Transforming this violence-ridden world. In C. Eppert \& H. Wang (Eds.), Cross-cultural studies in curriculum: Eastern thought, educational insights. Mahwah, NJ: Erlbaum/Routledge.

Fletcher, R. (2016). Connection with nature is an oxymoron: A political ecology of "nature-deficit disorder". Journal of Environmental Education, 22(5), 1-8.

Hitzhusen, G. E. (2006). Religion and environmental education: Building on common ground. Canadian Journal of Environmental Education, 11(1), 9-25.

Kabat-Zinn, J. (1994). Wherever you go there you are. New York: Hachette Books.

Larrivee, B., \& Cooper, J. M. (2006). An educator's guide to teacher reflection. Boston: Cengage Learning.

Meiklejohn, J., Phillips, C., Freedman, M. L., Griffin, M. L., Biegel, G., Roach, A., et al. (2012). Integrating mindfulness training into K-12 education: Fostering the resilience of teachers and students. Mindfulness, 3(4), 291-307.

Miller, J. P. (2007). The holistic curriculum (2nd ed.). Toronto, ON: University of Toronto Press.

Montgomery, L. M. (1915). Anne of green gables. Toronto, ON: L.C. Page \& Company.

Noddings, N. (1992). The challenge to care in schools. New York: Routledge.

Patton, M. Q. (2002). Qualitative research and evaluation methods (3rd ed.). Thousand Oaks, CA: Sage.

Rechtschaffen, D. (2014). The way of mindful education: Cultivating well-being in teachers and students. New York: W.W. Norton.

Sauvé, L. (2009). Being here together. In M. Mckenzie, P. Hart, B. Heesoon, \& B. Jickling (Eds.), Fields of green: Re-storying culture, environment and education (pp. 325-335). Cresskill, NJ: Hampton Press.

Shanker, S. (2013). Calm, alert and learning: Classroom strategies for self-regulation. Toronto, ON: Pearson Canada.

Stone, M. (2008). The inner tradition of yoga. Boston: Shambhala.

Thomashow, M. (1995). Ecological identity: Becoming a reflective environmentalist. Cambridge, MA: The MIT Press.

Zabel, A. (2013). Asana's first yoga class. Santa Monica, CA: AZIAM Books. 


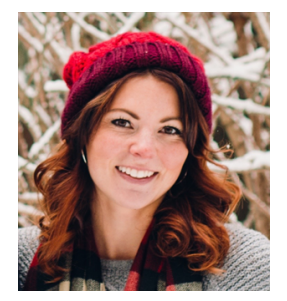

Leanne Glasser recently graduated with her Master of Education from Lakehead University in the Education for Change program with a specialization in Environment and Sustainability Education. Leanne is Canadian born and native to Thunder Bay, Ontario where her research was conducted. She is now living in California pursuing teaching, research, writing, and her love of the outdoors. Leanne considers herself to be a lifelong learner, always looking for new ways to implement environmental education and well-being into her teachings and writing. 